\title{
Empirical Pricing of Chinese Defaultable Corporate Bonds Based on the Incomplete Information Model
}

\author{
Li Ping and Wang Xiaoxu \\ Department of Finance, Beihang University, Beijing 100191, China \\ Correspondence should be addressed to Li Ping; lipingxx@126.com
}

Received 29 December 2013; Accepted 9 February 2014; Published 24 March 2014

Academic Editor: Chuangxia Huang

Copyright (C) 2014 L. Ping and W. Xiaoxu. This is an open access article distributed under the Creative Commons Attribution License, which permits unrestricted use, distribution, and reproduction in any medium, provided the original work is properly cited.

\begin{abstract}
The default of Suntech Power made the year 2013 in China "the first year of default" of bond markets. People are also clearly aware of the default risk of corporate bonds and find that fair pricing for defaultable corporate bonds is very important. In this paper we first give the pricing model based on incomplete information, then empirically price the Chinese corporate bond "11 super JGBS" from Merton's model, reduced-form model, and incomplete information model, respectively, and then compare the obtained prices with the real prices. Results show that all the three models can reflect the trend of bond prices, but the incomplete information model fits the real prices best. In addition, the default probability obtained from the incomplete information model can discriminate the credit quality of listed companies.
\end{abstract}

\section{Introduction}

Because of the subprime crisis and the European sovereign debt crisis, global economy has been seriously hit. Subsequently, Standard and Poor downgraded the US credit rating. In China, the no default phenomenon in bond markets was broken by the default of the Suntech Power in 2013. So the year 2013 in China became "the first year of default" of bond markets.

The year 2012 was of great significance for Chinese bond market. The United Credit indicated that there were 4 defaults in Chinese interbank bond market during 2012. The overall default probability of corporate bonds was 0.17 if in terms of the bond maturity and 0.12 if in terms of bond issuance. This means that the year 2012 was a new starting point of Chinese bond market. The company Chaori Solar Energy has attracted public attention since the issuance. And due to the high default risk, it was once predicted to be the first default of domestic bonds.

Because of the higher and higher default risk for Chinese corporate bond, it is very important to study the issues of pricing and risk management for defaultable bonds. There are three main models for defaultable bond pricing: the traditional structural model [1] and reduced-form model
[2] and the emerging incomplete information model. The traditional models are carried out under the assumption of perfect information and that default can be measured by observable changes in the asset value. However, in the real world, the volatility and growth rate of a company's asset value cannot be directly observed, which makes the default probability based on the traditional model biased with the actual situation and also leads to the result that the expected absolute level is low. Therefore, Duffie and Lando [3] relaxed the complete information assumptions in traditional models and proposed the incomplete information model. Then Giesecke and Goldberg [4] and Liu [5] further investigated the incomplete information model under the assumption of incomplete information and gave different types of incomplete information model.

In this paper, we give a new pricing formula for defaultable corporate bonds by combining the incomplete information model with the credit risk premium based on default probability. Then we calculate the default probability and price for the Chinese corporate bond "11 super JGBS" from the three models: structural model, reduced-form model, and incomplete information model. Results show that all the three models can reflect the trend of bond prices, but the incomplete information model can fit the real prices best and 
can discriminate the credit quality of listed companies more effectively.

The rest of the paper is organized as follows. In Section 2, we introduce the traditional pricing models for defaultable corporate bonds. Then in Section 3 we propose a new pricing model based on the incomplete information model and the credit risk premium. An empirical calculation is given in Section 4, and then Section 5 concludes the paper.

\section{Traditional Pricing Models for Defaultable Bonds}

In this section, we will introduce the two traditional pricing models: Merton's structural model and reduced-form model.

2.1. Structural Model. The structural model was first put forward by Merton [1] and then extended by Black and Cox [6], in which the company's debt is regarded as a contingent claim of the company's assets. When the company's asset value is lower than its liabilities, the company will go bankrupt. The value of equity can be obtained by the Black-Scholes option pricing model [7], and the debt value is the company's total value minus the equity value.

In this paper, we assume that stocks and bonds constitute the company's assets structure. In Merton's model, if the asset value is lower than the liability value at the maturity of debt, the corporate defaults. He assumed that the value of corporate bonds basically depends on three factors: the rate of return of a risk-free bond, default probability, and various regulations and restrictions in the bond terms such as maturity date, coupon rate, seniority of default event, and sinking fund.

2.2. Reduced-Form Model. The reduced-form model assumes that the default is exogenous and will occur with no warnings. It directly defines the default time according to default intensity, which avoids to model the unobservable corporate value. The representative work includes Jarrow and Turnbull [2] and Duffie and Singleton [8]. They treated the default as a jump process, and the default process can depend on exogenous macrostate variables. The reduced-form model has the following characteristics: (1) it assumes that the market was complete which is accordant with the no-arbitrage assumption; (2) the credit risk can be obtained by the default probability; (3) the default is a random process; (4) the default recovery rate is an exogenous variable.

The reduced-form model does not consider the relationship between the default and corporate value, so some researchers made some extension. In the reduced-form model, default time is decided by the first jump of the exogenous jump process and the parameters of default intensity are given by the market data, and information can be observed in the market. However, the real market is asymmetric, and we can hardly avoid the information distortion. Therefore, in addition to the part information of the company's assets and liabilities, other information such as the default boundaries is difficult to observe.

\section{The Incomplete Information Model Combined with Credit Risk Premium}

Different from the traditional models, the incomplete information model is to analyze credit risk based on incomplete information. In reality, default occurs when there is no omen, and the information about company's asset value and default boundary cannot be completely observed by investors. That is, the information is incomplete. We cannot predict when default occurs and cannot price the bond according to the exact asset value and default boundaries.

Under the condition that the information about company's asset value and boundaries is not complete, investors can only observe the default according to Giesecke [9]. When companies issue bonds, they only announce their initial debt value $V_{0}$ to investors. Then after they issue the bonds, investors receive the incomplete information about corporate value such as the company's accounting statements with noise.

We use a complete probability space $(\Omega, \mathfrak{I}, P)$ to represent the uncertainty and use $\mathfrak{J}_{t}$ to denote the information filtration. From the information incompleteness we know that corporate value $V_{t} \notin \mathfrak{I}_{t}$. We then assume that $V_{t}$ follows a geometric Brownian motion with volatility $\sigma$ and drift $\mu=$ $m-(1 / 2) \sigma^{2} . M_{t}$ is used to denote the historical lowest value of the company; then the distribution of $M_{t}$ is

$$
\begin{aligned}
\Psi(t, x) & =P\left(M_{t} \leq x\right) \\
& =\Phi\left(\frac{x-\mu t}{\sigma \sqrt{t}}\right)+\exp \left(\frac{2 \mu x}{\sigma^{2}}\right) \Phi\left(\frac{x+\mu t}{\sigma \sqrt{t}}\right),
\end{aligned}
$$

where, $\Phi$ is the standard normal distribution.

Then the derivative of $\Psi(t, x)$ with respect to $t$ is

$$
\begin{array}{r}
\varphi(t, x)=\frac{1}{2 \sigma}\left[\left(\frac{\mu}{\sqrt{t}}-\frac{x}{\sqrt{t^{3}}}\right) e^{2 \mu x / \sigma^{2}} \phi\left(\frac{x+\mu t}{\sigma \sqrt{t}}\right)\right. \\
\left.-\left(\frac{\mu}{\sqrt{t}}+\frac{x}{\sqrt{t^{3}}}\right) \phi\left(\frac{\mu t-x}{\sigma \sqrt{t}}\right)\right],
\end{array}
$$

where $\phi$ is the standard normal density function.

Duffie and Lando [3] showed that when the default boundary $D$ is known, the price trend $A_{t}$ satisfies

$$
A(t)=\int_{0}^{t} \lambda_{s} d s
$$

where $\lambda_{t}=\varphi(t, d) /(1-\Psi(t, d))$ is the default density, $d=$ $\ln (D)$

We use $\tau$ to denote the default time; then its conditional distribution is

$$
\begin{aligned}
p(t, T) & =P\left(\tau \leq T \mid \Im_{t}\right)=1-E\left[\exp \left(-\int_{t}^{T} \lambda_{s} d s \mid \Im_{t}\right)\right] \\
& =\frac{\Psi(T, d)-\Psi(t, d)}{1-\Psi(t, d)} .
\end{aligned}
$$

For $t \geq 0$, the conditional distribution of $M_{t}$ with respect to $\mathfrak{\Im}_{t}$ is assumed to be $H(t, x)$. From the information 
TABLE 1: Basic information of the bond.

\begin{tabular}{lcccccc}
\hline Bond code & Bond name & Bond issuer & Issue date & Maturity date & Credit rating & Coupon rate \\
\hline 112061 & 11 super JGBS & Shanghai Chaori Solar Energy Science & $07-03-2012$ & $07-03-2017$ & A & $8.98 \%$ \\
\hline
\end{tabular}

TABLE 2: Estimates of related parameters.

\begin{tabular}{lccccccc}
\hline Parameters & $\sigma_{e}$ & $\sigma_{V}$ & $\mu_{e}$ & $t$ & $T$ & Default probability & Bond price \\
\hline Estimation & 0.61 & 0.36 & -0.73 & 1.32 & 5 & $37.37 \%$ & 102.36 \\
\hline
\end{tabular}

incompleteness we know that $H(t, x)$ is continuous and increasing. Then from Duffie and Lando [3], the conditional survival probability $L_{t}$ is

$$
L_{t}=1-\int_{-\infty}^{V_{0}} H(t, x) d G(x)
$$

where $G(x)=e^{x}, x<0$. If the price trend $A_{t}$ is continuous, then

$$
A_{t}=-\log \left(1-\int_{-\infty}^{V_{0}} H(t, x) d G(x)\right)
$$

When investors can only observe the default we have

$$
H(t, x)=\Psi(t, x) .
$$

Assuming that $V_{0}=0$, then

$$
A_{t}=-\log \left[1-\int_{-\infty}^{0} \Psi(t, x) e^{x} d x\right] .
$$

Together with (3) we obtain

$$
\begin{aligned}
p(s, v)= & \Phi\left(\frac{-v-\mu s}{\sigma \sqrt{s}}\right)-e^{v+s m} \Phi\left(\frac{-v-v s}{\sigma \sqrt{s}}\right) \\
& +\frac{1}{\gamma} e^{(1-\gamma) v} \Phi\left(\frac{\mu s-v}{\sigma \sqrt{s}}\right)-\frac{1}{\gamma} e^{v+s \beta} \Phi\left(\frac{\delta s-v}{\sigma \sqrt{s}}\right),
\end{aligned}
$$

where $v=\mu+\sigma^{2}, \gamma=1+\left(2 \mu / \sigma^{2}\right), \delta=\mu-\gamma \sigma^{2}, \beta=-\mu \gamma+$ $\gamma^{2} \sigma^{2} / 2$.

For simplicity we set $\Gamma=\sqrt{t} / \sigma$; then

$$
\begin{aligned}
p(t, 0)= & \Phi(-\mu \Gamma)+e^{t m} \Phi(-v \Gamma) \\
& +\frac{1}{\gamma} \Phi(\mu \Gamma)-\frac{1}{\gamma} e^{t \beta} \Phi(\delta \Gamma) .
\end{aligned}
$$

From (2) and (9) we get

$$
A_{t}=-\log (1-p(s, 0)), \quad \lambda_{t}=\frac{p(t, 0)}{1-p(t, 0)}
$$

Then the default probability is

$$
\begin{aligned}
p(t, T) & =P\left(\tau \leq T \mid \varsigma_{t}\right)=1-e^{A_{t}-A_{T}} \\
& =1-e^{-\int_{t}^{T} \lambda_{s} d s}=\frac{p(T, 0)-p(t, 0)}{1-p(t, 0)} .
\end{aligned}
$$

From the above formulas we can see that, for different hypothesis about the information of the corporate value and default boundary, the default probability and credit risk premium are different.

Let $r$ be the risk-free interest rate; let $R_{t}$ and $p_{t}$ be the yield and default probability of the corporate bond at time $t$, respectively. Then for a single period bond, $\left(1+R_{t}\right)\left(1-p_{t}\right)=$ $1+r$; that is,

$$
R_{t}=r+\frac{p_{t}}{1-p_{t}}(1+r) .
$$

We put $s=(p /(1-p))(1+r)$; then $s$ is the credit risk premium of the corporate bond.

For multiperiod corporate bond, we assume that $r_{i}(i=$ $1,2, \ldots, n)$ is the risk-free interest rate for maturity $i, s_{i}$ is the credit risk premium, and $C_{i}$ is the cash flow; then the expected price of a corporate bond is

$$
P=\sum_{i=1}^{n} \frac{C_{i}}{\left(1+r_{i}+s_{i}\right)} .
$$

This is the formula for pricing a corporate bond considering the credit risk premium. In the next section we will use this formula to empirically calculate the price for a Chinese corporate bond and compare the prices obtained from (14) with those obtained from the traditional structural model and reduced-form model.

\section{Empirical Pricing}

In this section, we choose the "11 super JGBS" bond with high default risk for empirical analysis. The "11 super JGBS" bond was issued by Shanghai Chaori Solar Energy Science Company. When it was first issued, Pengyuan Credit Bureau rated it as AA; then on December 27,2012, it was downgraded to $\mathrm{AA}-$,, then on April 10, 2013, to BBB +, and finally on May 20, 2013, to CCC.

On December 20, 2012, the stocks and bonds of Shanghai Chaori Solar Energy Science were both suspended, so we select the data of "11 super JGBS" from April 20, 2012, to December 19, 2012, for empirical research. Table 1 is about the basic information of the bond.

Firstly, we calculate the default probability and the price of "11 super JGBS" based on the incomplete information model. Under this model, we calculate the asset value $V$ and its volatility $\sigma_{v}$ and the company stock value $E$ and its volatility $\sigma_{e}$ as well as its draft term $\mu_{e}$, respectively. Then we use Matlab to estimate the parameters and get the results as shown in Table 2. 
TABLE 3: Moody's credit rating standard.

\begin{tabular}{lccccccc}
\hline Credit ratings & Aaa & Aa & A & Baa & Ba & B & C \\
\hline Default probability (\%) & $<0.02$ & $0.02-0.04$ & $0.04-0.08$ & $0.08-0.2$ & $0.2-1.8$ & $1.8-8.3$ & $>8.3$ \\
\hline
\end{tabular}

Table 3 is Moody's credit rating standard, from which we can see that, under the incomplete information model, "11 super JGBS" bond has a high default probability and is already a junk bond. But in reality, the bond rating remains at A level. Since 2012, the company has experienced a series of credit events such as delinquent loans, stagnation of production, and investigation by the regulators. The suspension of the bond on December 20, 2012, also verifies the truth that the default probability is very high. Investors are very concerned with the bond's credit risk, so the incomplete information model can effectively discriminate the bonds with high risk.

Next, we calculate the default probability for the sample period every 5 days based on the asset's volatility under three models and get Figure 1.

Combining with Table 3 , we can see that, during the sample periods, the default probabilities estimated from Merton's model and the reduced-form model are significantly less than those obtained from the incomplete information model. For the two traditional models, the bond credit rating remains at A level. Only for some points obtained from Merton's model, the estimated credit rating falls to Baa. However, the default probability estimated from the incomplete information model has been rising, and the credit rating is falling. It indicates that the incomplete information model is most sensitive to the change of company information, so it can detect the changes in the credit quality quickly. Therefore the incomplete information model can effectively discriminate the credit risk of listed companies.

We then calculate the bond's theoretical prices for the sample period every 5 days based on the asset's volatility under the three models and compare them with the real prices, which are shown Figure 2.

From Figure 2 we can see that all the three models can reflect the general trend of bond prices, but in comparison, the incomplete information model fits the real prices and reflects the basic movements of prices better. In addition, influenced by bad information such as reduced performance and credit downgrade, the default risk of the bond is expanding fast. For example, on December 20, the stock of Chaori Solar Energy Science Company was suspended. Based on historical information of the company, the incomplete information model reflects the surge of credit risk.

Finally, we make the sensitivity analysis by letting the asset's volatility range from 0.02 to 0.06 and the risk-free interest rate from 0.0314 to 0.072 . Results are shown in Figure 3.

In Figure 3, the $x$-, $y$-, and $z$-axes represent the asset's volatility, the risk-free interest rate, and the bond price, respectively. We can see that the higher the asset's volatility, the higher the bond price, and the higher the risk-free interest rate, the lower the bond price. And the bond price is more sensitive to the asset's volatility. So the asset's volatility is an important factor influencing the bond price.

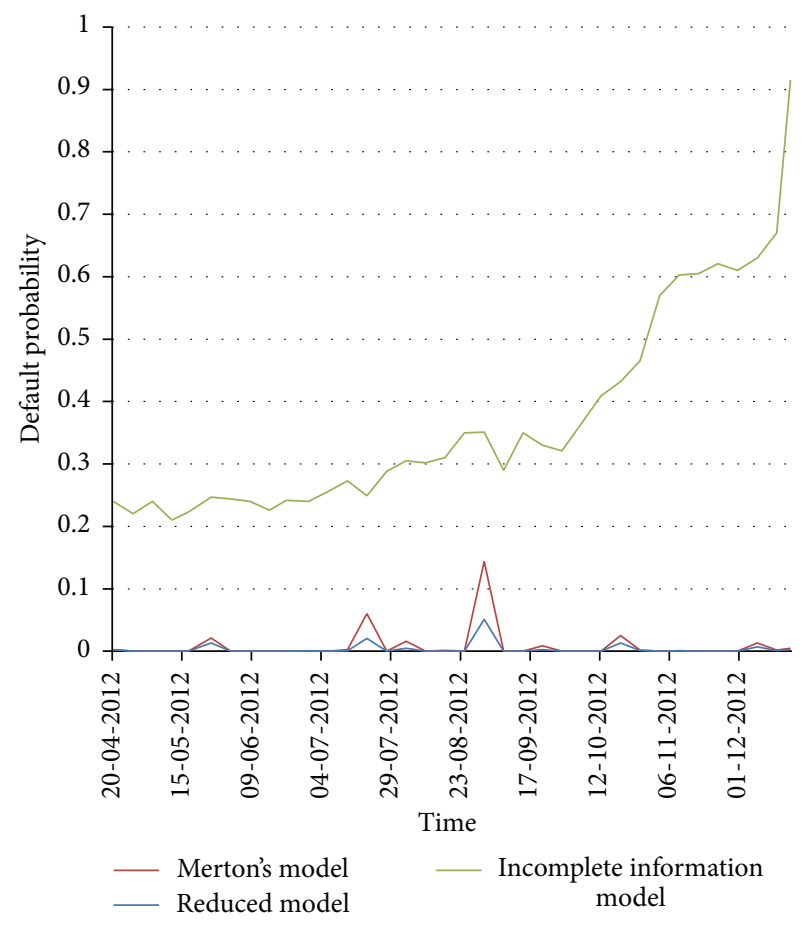

FIgURE 1: Default probabilities of "11 super JGBS" bond under three models.

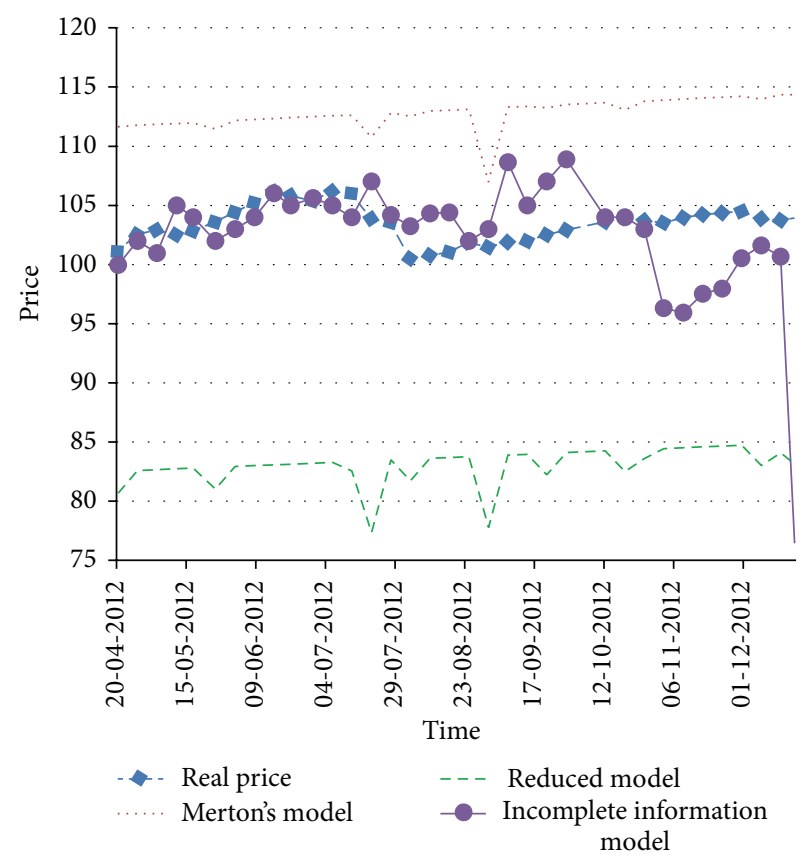

FIGURE 2: Comparison of the bond's prices. 


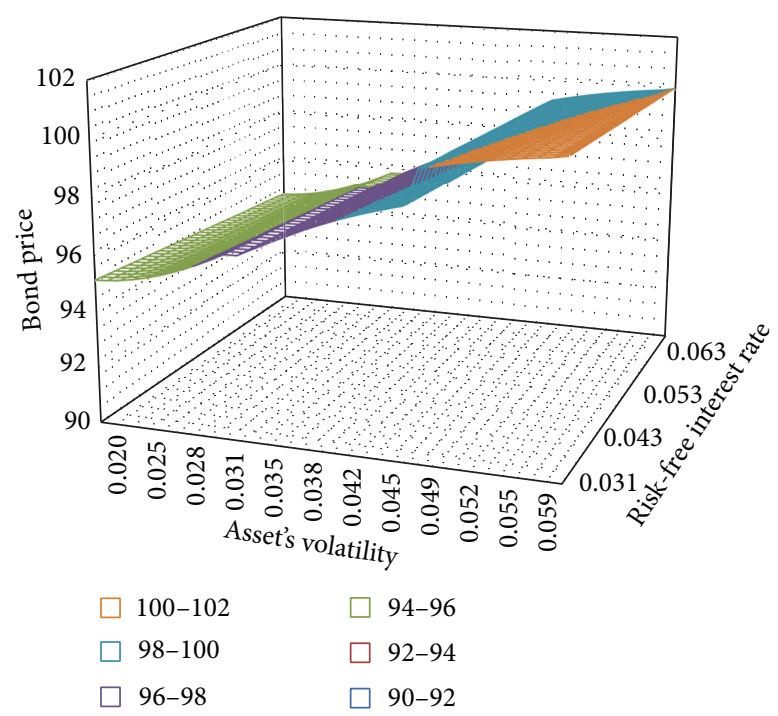

FIGURE 3: Sensitivity analysis.

\section{Conclusions}

In this paper, we extend the incomplete information model by combining with the credit risk premium and redefined the pricing formula for defaultable corporate bonds. By comparing the three models, we find that the incomplete information model is a better method to identify and distinguish between bond credit ratings. It can also fit bond prices better and reflect the change of company information more sensitively. Suntech's default broke the no-default phenomenon in Chinese bond market, which means that the impact of listed company's credit risk is more and more important. We think that the incomplete information model is more effective to price defaultable corporate bonds and will provide new thoughts for investors to avoid credit risk.

In recent years, some researchers use the structural model and reduced-form model to study the default correlation and then price defaultable bonds and credit derivatives, such as Yu [10], P. Li and Z. Z. Li [11], and Wen and Liu [12]. In our next research, we will use the incomplete information model combined with copula function to study the default correlation and price defaultable bonds and credit derivatives.

\section{Conflict of Interests}

The authors declare that there is no conflict of interests regarding the publication of this paper.

\section{Acknowledgment}

This work was supported by the National Natural Science Foundation of China (nos. 71271015, 70971006).

\section{References}

[1] C. R. Merton, "On the pricing of corporate debt: the risk structure of interest rates," The Journal of Finance, vol. 29, no. 2, pp. 449-470, 1974.
[2] R. Jarrow and S. Turnbull, "Pricing derivatives on financial securities subject to credit risk," The Journal of Finance, vol. 50, no. 1, pp. 53-85, 1995.

[3] D. Duffie and D. Lando, "Term structures of credit spreads with incomplete accounting information," Econometrica, vol. 69, no. 3, pp. 622-664, 2001.

[4] K. Giesecke and L. Goldberg, "Sequential defaults and incomplete information," Journal of Risk, vol. 7, no. 1, pp. 1-26, 2004.

[5] X. F. Liu, The researeh on default risk of corporate bond based on incomplete information model [M.S. thesis], Jinan University, Guangzhou, China, 2008.

[6] F. Black and J. Cox, "Valuing corporate securities: some effects of bond indenture provisions," The Journal of Finance, vol. 31, no. 2, pp. 351-367, 1976.

[7] F. Black and M. Scholes, "The Pricing of Options and Coporate Liabilities," Joumal of Political Eeonomy, no. 81, pp. 637-654, 1973.

[8] D. Duffie and K. J. Singleton, "Modeling term structures of defaultable bonds," Review of Financial Studies, vol. 12, no. 4, pp. 687-720, 1999.

[9] K. Giesecke, "Default and information," Journal of Economic Dynamics and Control, vol. 30, no. 11, pp. 2281-2303, 2006.

[10] F. Yu, "Correlated defaults and the valuation of defaultable securities," in Proceedings of the 2nd International Conference on Credit Risk, pp. 1-30, 2004.

[11] P. Li and Z. Z. Li, "Change analysis for the dependence structure and dynamic pricing of basket default swaps," European Financial Management, 2013.

[12] F. H. Wen and Z. F. Liu, "A copula-based correlation measure and its application in chinese stock market," International Journal of Information Technology and Decision Making, vol. 8, no. 4, pp. 787-801, 2009. 


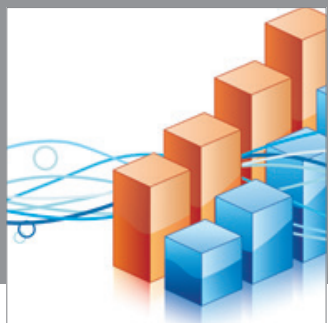

Advances in

Operations Research

mansans

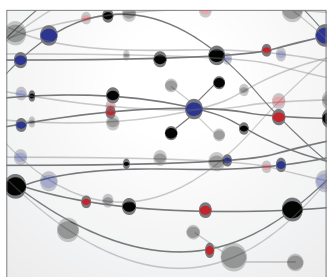

The Scientific World Journal
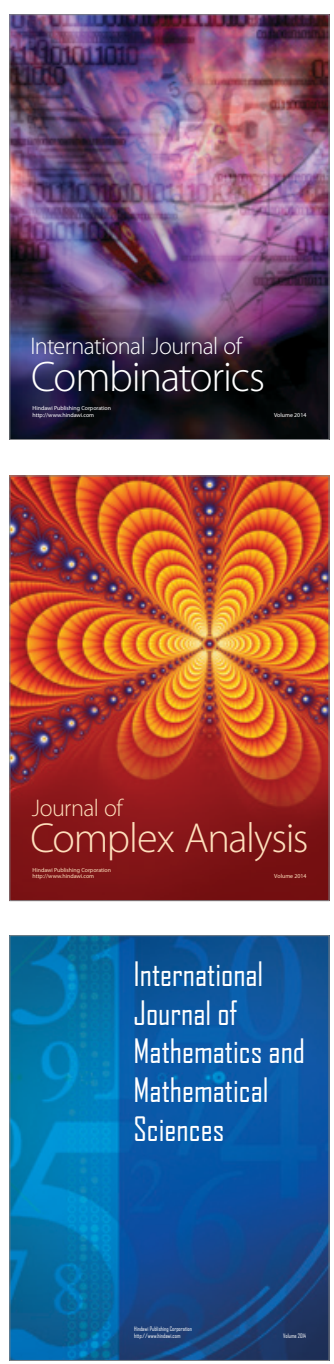
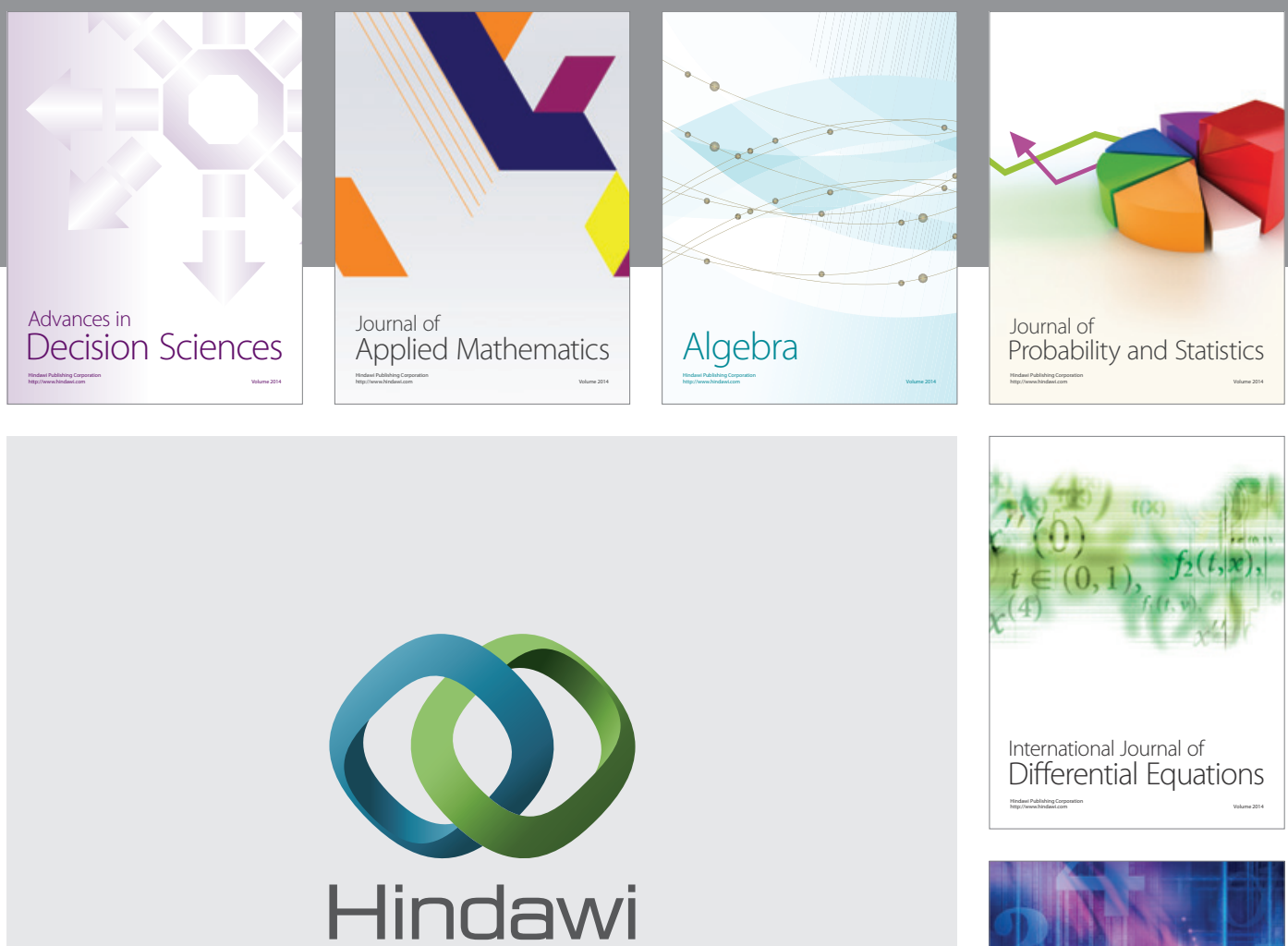

Submit your manuscripts at http://www.hindawi.com
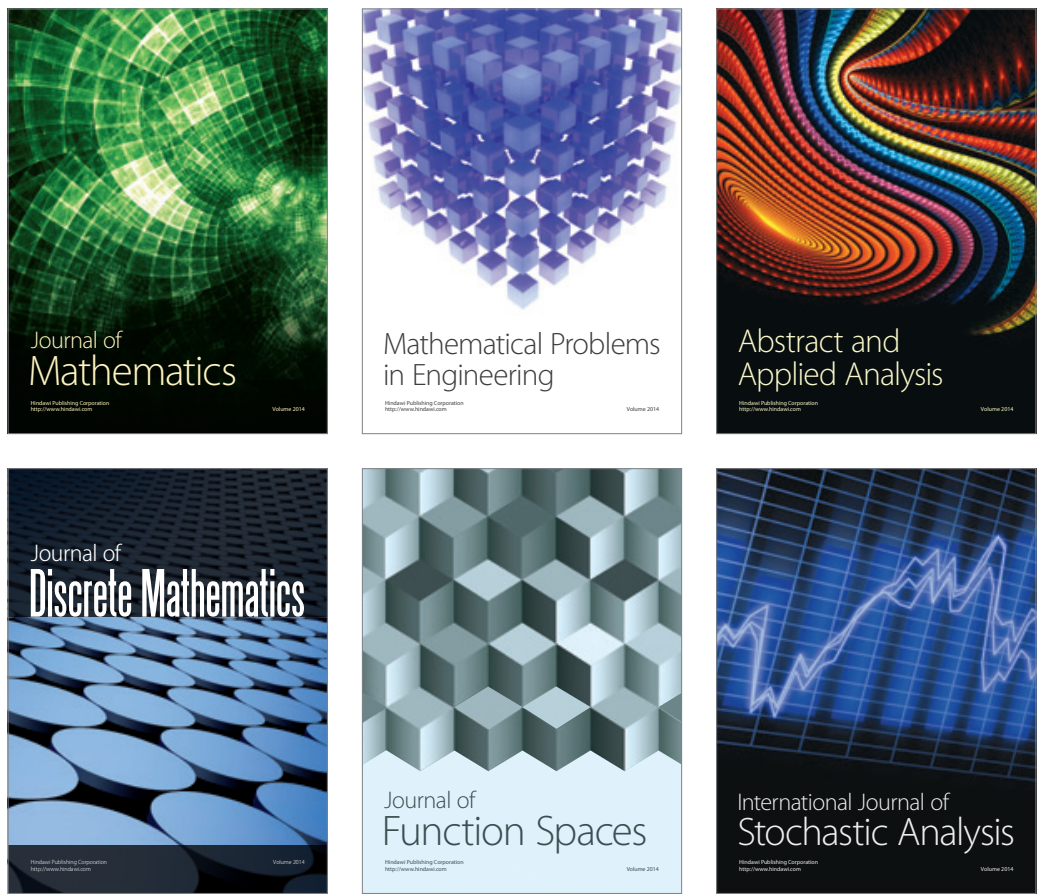

Journal of

Function Spaces

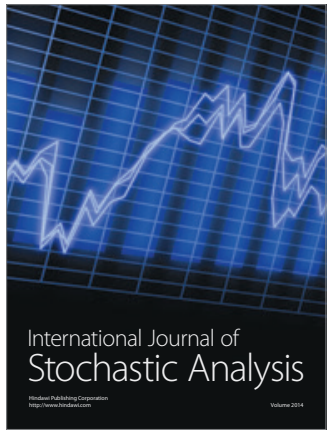

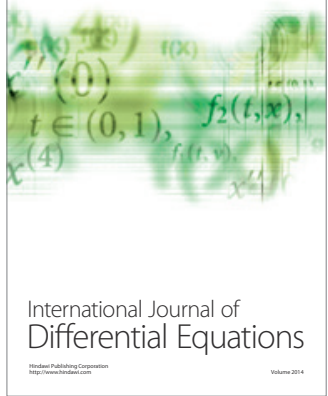
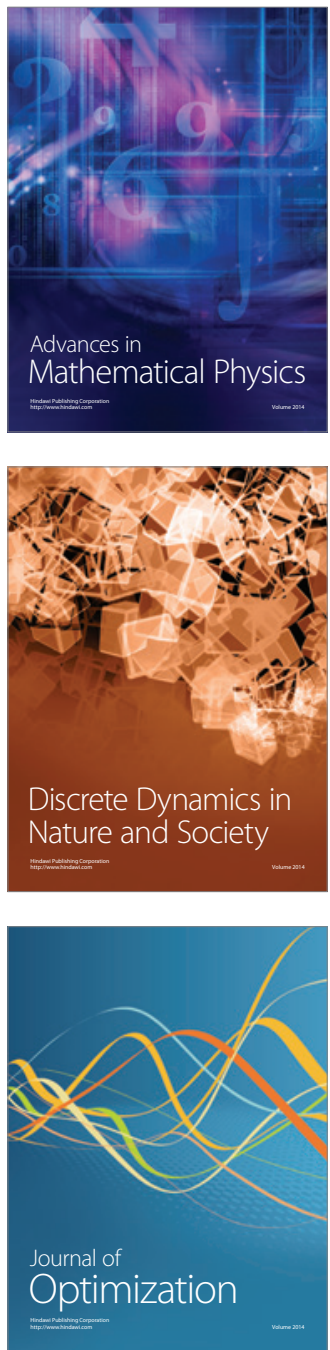